\title{
Prey density in non-breeding areas affects adult survival of black-legged kittiwakes Rissa tridactyla
}

\author{
Tone K. Reiertsen ${ }^{1,2, *}$, Kjell E. Erikstad ${ }^{2,3}$, Tycho Anker-Nilssen ${ }^{4}$, Robert T. Barrett ${ }^{1}$, \\ Thierry Boulinier ${ }^{5}$, Morten Frederiksen ${ }^{6}$, Jacob González-Solís ${ }^{7}$, David Gremillet ${ }^{5}$, \\ David Johns ${ }^{8}$, Børge Moe ${ }^{4}$, Aurore Ponchon ${ }^{5}$, Mette Skern-Mauritzen ${ }^{9}$, \\ Hanno Sandvik ${ }^{3}$, Nigel G. Yoccoz ${ }^{10}$ \\ ${ }^{1}$ Tromsø University Museum, Department of Natural Sciences, 9037 Tromsø, Norway \\ ${ }^{2}$ Norwegian Institute for Nature Research, \\ FRAM - High North Research Centre for Climate and the Environment, Hjalmar Johansens gt 14, 9296 Tromsø, Norway \\ ${ }^{3}$ Centre for Biodiversity Dynamics, Norwegian University of Science and Technology, 7491 Trondheim, Norway \\ ${ }^{4}$ Norwegian Institute for Nature Research, PO Box 5685 Sluppen, 7485 Trondheim, Norway \\ ${ }^{5}$ Centre d'Ecologie Fonctionnelle et Evolutive, CNRS UMR 5175, 1919 Route de Mende, 34293 Montpellier cedex 5, France \\ ${ }^{6}$ Department of Biosciences, Aarhus University, Fredriksborgvej 399, 4000 Roskilde, Denmark \\ ${ }^{7}$ Institut de Recerca de la Biodiversitat (IRBio) and Departament de Biologia Animal (Vertebrats), Facultat de Biologia, \\ Universitat de Barcelona, Av. Diagonal 643, 08028 Barcelona, Spain \\ ${ }^{8}$ Sir Alister Hardy Foundation for Ocean Science (SAHFOS), Citadel Hill, PL1 2PB Plymouth, UK \\ ${ }^{9}$ Institute of Marine Research, PO Box 1870, 5817 Bergen, Norway \\ ${ }^{10}$ Department of Arctic and Marine Biology, Faculty of Biosciences, Fisheries and Economics, University of Tromsø, \\ 9037 Tromsø, Norway
}

\begin{abstract}
In migratory birds, environmental conditions in both breeding and non-breeding areas may affect adult survival rates and hence be significant drivers of demographic processes. In seabirds, poor knowledge of their true distribution outside the breeding season, however, has severely limited such studies. This study explored how annual adult survival rates of black-legged kittiwakes Rissa tridactyla on Hornøya in the southern Barents Sea were related to temporal variation in prey densities and climatic parameters in their breeding and non-breeding areas. We used information on the kittiwakes' spatiotemporal distribution in the non-breeding season gained from year-round light-based tracking devices (geolocators) and satellite transmitters, and kittiwake annual adult survival rates gained from a multistate capture-mark-recapture analysis of a 22 yr time series of colour-ringed kittiwakes. In the post-breeding period, kittiwakes concentrated in an area east of Svalbard, in the winter they stayed in the Grand Banks/Labrador Sea area, and in the pre-breeding period they returned to the Barents Sea. We identified 2 possible prey categories of importance for the survival of kittiwakes in these areas (sea butterflies Thecosomata in the Grand Banks/Labrador Sea area in winter and capelin Mallotus villosus in the Barents Sea in the pre-breeding season) that together explained $52 \%$ of the variation in adult survival rates. Our results may have important implications for the conservation of kittiwakes, which are declining globally, because other populations use the same areas. Since they are under the influence of major anthropogenic activities including fisheries, international shipping and the offshore oil and gas industry, both areas should be targeted for future management plans.
\end{abstract}

KEY WORDS: Black-legged kittiwake · Pteropods · Capelin · Capture-mark-recapture analyses · Non-breeding distribution 


\section{INTRODUCTION}

The relationship between adult survival in longlived migratory species and environmental conditions in both breeding and non-breeding areas is important in understanding demographic processes and population dynamics. For many migratory birds, however, including most marine birds, the very limited knowledge of their distribution outside of the breeding season has constrained studies of the relationship between demography and environmental conditions (Runge \& Marra 2005, Ratikainen et al. 2008, Schaub et al. 2011, Smith \& Gaston 2012). For pelagic seabirds, of which many species are severely threatened by global extinction, such studies are crucial (Croxall et al. 2012, Frederiksen et al. 2012, Lewison et al. 2012).

The recent advance of tracking technologies, such as miniaturized year-round light-based tracking devices (GLS loggers or hereafter geolocators), has revolutionized our knowledge of the non-breeding range of migrant species (e.g. Phillips et al. 2004, GonzálesSolís et al. 2007, Guilford et al. 2009, Egevang et al. 2010, Seavy et al. 2012, Smith \& Gaston 2012). Combining such data with statistical modeling of longterm capture-mark-resighting (CMR) data now allows us to explore in detail the relationships between environmental conditions in both breeding and nonbreeding areas and adult survival rates. As yet, very few studies have investigated such relationships (but see Schaub et al. 2011), and we know of only 2 seabird studies that link adult survival to environmental conditions in both the breeding and non-breeding areas (Ramos et al. 2012, Smith \& Gaston 2012) and none that address temporal changes in prey availability in non-breeding areas and adult survival rates.

Even small changes in adult survival can significantly impact the population dynamics in long-lived seabirds, since adult survival has a strong effect on lifetime reproduction (Lebreton \& Clobert 1991, Stearns 1992). Worrying in this respect is the growing number of studies documenting a negative impact of climate on the adult survival rates of marine birds (e.g. Harris et al. 2005, Jenouvrier et al. 2005, Sandvik et al. 2005, LeBohec et al. 2008). Climatic effects are, however, most often indirectly mediated through temporal changes in prey availability, via changes in prey abundance (e.g. Sandvik et al. 2005), but they may also affect prey availability directly through shifts in the prey's spatial distribution (e.g. Peron et al. 2010).

Most marine ecosystems show pronounced temporal and spatial variation in oceanographic processes and trophic interactions that are often driven by cli- matic processes, and these may lead to fluctuations in important fish stocks and disruptions in predator-prey interactions (Godø 2003, Durant et al. 2005, Grebmeier et al. 2006, Gjøsæter et al. 2009, Stige et al. 2010, Certain et al. 2011). Especially for top predators such as seabirds, such fluctuations in prey species may have negative effects on both survival and reproduction (Lack 1968, Cairns 1992, Furness 2003, Oro et al. 2004, Cury et al. 2011) and in some cases may even drive populations towards extinction (Erikstad et al. 2013).

Since day length and food availability tend to be at a minimum in winter, conditions in the wintering range may strongly influence survival (Gaston 2003, Frederiksen et al. 2008a). The effects of environmental variation on adult survival may, therefore, be more profound outside the breeding season (Schaub et al. 2011, Smith \& Gaston 2012). However, during the breeding season, the costs of reproduction are also known to impact survival (Golet et al. 1998, Oro \& Furness 2002), and may also have direct effects on subsequent winter ecology (so called carry-over effects) (Golet et al. 1998, Ylönen et al. 1998, Harrison et al. 2010). To be able to determine what factors and time periods have the greatest impact on adult survival, it is important to consider factors in both the breeding and non-breeding seasons.

The Atlantic population of the black-legged kittiwake Rissa tridactyla (hereafter kittiwake) has experienced widespread population declines in recent decades (Frederiksen 2010). The Norwegian population has decreased by 6-8\% per year since the mid1990s (Barrett et al. 2006) and is currently categorized as endangered on the Norwegian Red List (Kålås et al. 2010). The reasons for the declines over such a large scale are not fully understood, but there are indications that food shortages, possibly linked to an increase in fishery activity, are important (e.g. Frederiksen et al. 2004, 2008b, 2012).

Kittiwakes are good candidate species as sentinels of environmental change in the marine system. They are surface feeders with limited capacity to switch prey, and they seem to operate at their energetic ceiling (Welcker et al. 2010), which makes them particularly vulnerable to changes in the marine system (Furness \& Tasker 2000). As such, both spatial and temporal environmental changes can affect their demographic traits. A recent study by Frederiksen et al. (2012) documented the non-breeding distribution of kittiwakes from a widespread selection of colonies across the North Atlantic (including the present study population), providing the unique opportunity to extract environmental covariates (such as sea sur- 
face temperature [SST] and temporal data of prey density) from the identified non-breeding areas and combine them with important demographic traits, such as adult survival rates.

In order to collate representative data on prey availability for kittiwakes in their non-breeding areas, knowledge of their diet throughout the year is important. Such data stem, however, mainly from the breeding season, when the kittiwakes predominantly feed on invertebrates and small energy-rich schooling fish (up to $15-20 \mathrm{~cm}$ ), the composition of which differs between different ecosystems. In the North Sea, they mainly feed on lesser sandeel Ammodytes marinus (Lewis et al. 2001), in the Newfoundland and Labrador Sea area on capelin Mallotus villosus (Carscadden et al. 2002), and in the Barents Sea they switch between capelin and herring Clupea harengus (Barrett 2007). In the pre-breeding season, polar cod Boreogadus saida have been found in stomach samples of kittiwakes (Erikstad 1990). Knowledge of their diet in the non-breeding season is poor (e.g. Frederiksen et al. 2012), but a study by González-Solís et al. (2011) of kittiwakes breeding on Hornøya suggests that they feed on a lower trophic level (zooplankton) outside of the breeding season. Some studies have shown that they may feed on a variety of large zooplankton species, e.g. Calanus spp., amphipods (Hyperiidea), euphausiids and pteropods (Thecosomata) (Lydersen et al. 1989, Mehlum \& Gabrielsen 1993, Lewis et al. 2001, Karnovsky et al. 2008).

The aim of the present study was to explore the relationship between potential prey availability and climatic factors from known non-breeding areas and adult survival rates of kittiwakes breeding in a colony in the southern Barents Sea. Our main goal was to assess which environmental conditions and which time period had the greatest impact on this key demographic trait. By combining tracking data of kittiwakes from the colony and knowledge of kittiwake diet in their main non-breeding areas, we were able to extract data on potential important environmental factors from large-scale databases and enter them as covariates in a multistate CMR analysis and, hence, assess their impact on annual adult survival rate of kittiwakes from the study colony.

\section{MATERIALS AND METHODS}

We used a 22 yr (1990-2011) time series of resighted breeding kittiwakes that were individually marked with colour- or letter-coded rings at the colony of Hornøya $\left(70^{\circ} 23^{\prime} \mathrm{N}, 31^{\circ} 09^{\prime} \mathrm{E}\right)$ in the south- ern Barents Sea, where searches for the birds were made every year during the breeding season and where the population has declined by $70 \%$ since 1990 (Barrett et al. 2006).

Kittiwakes are long-lived, cliff-nesting seabirds that lay 1-3 eggs and have a circumpolar, subarctic and Arctic distribution (Coulson 2011). Their mean breeding life-span on Hornøya in 1989-2003 was estimated to be 8 yr (Sandvik et al. 2005); however, one individual was sighted at an age of $>26$ yr (Barrett 2010).

\section{Non-breeding distribution}

The non-breeding distribution of adult kittiwakes in the North Atlantic has recently been extensively mapped using light level geolocators (Bogdanova et al. 2011, González-Solís et al. 2011, Frederiksen et al. 2012). The data used in this study concern birds nesting on Hornøya, which were used in both the 20082009 study by González-Solís et al. (2011) and in 2008-2009 and 2009-2010 by Frederiksen et al. (2012). These data give important information on the non-breeding distribution of the study population and are used as background information for the analysis in the present study. The initial data processing is detailed in Frederiksen et al. (2012). Birds were tracked from one breeding season to the next $(\mathrm{n}=6$ in 2008-2009, n = 14 in 2009-2010) and the monthly data included in the present study are 1-10 September, 21-31 October, 1-30 November, 1-31 December, 1-31 January, 1-20 February and 4-30 April. Data from July and August were excluded because of the constant daylight in the Barents Sea. Data around the equinoxes were also excluded because latitude estimates are then unreliable (Phillips et al. 2004).

We also included data from 5 adult kittiwakes nesting in Hornøya deployed with platform terminal transmitters (PTTs or hereafter satellite transmitters; A. Ponchon et al. unpubl.) from $2010(n=5)$. Fixed kernel densities of kittiwake distribution were estimated with Hawth's Analysis Tools for ArcGis using the quartic approximation and a raster cell size of $20 \mathrm{~km}$ (Beyer 2004). The smoothing factor (also known as band width or the $h$ statistic) was 50 and $200 \mathrm{~km}$ for the satellite transmitter and geolocator data, respectively. Kernel contours (\%) are presented in maps with a North Pole stereographic projection.

In 2008, 2009 and 2010, all kittiwakes nesting in Hornøya equipped with geolocators and satellite transmitters went straight north after the breeding season to an area east of the Svalbard archipelago 
(EOS hereafter) (between $75^{\circ} \mathrm{N}$ and $80^{\circ} \mathrm{N}$, and $15^{\circ} \mathrm{E}$ and $35^{\circ} \mathrm{E}$ ) and stayed there until October (Figs. 1A,B \& 2C). In October they started to migrate west towards the Grand Banks/Labrador Sea area (GBLS hereafter) in the NW Atlantic (Fig. 1B), where most birds stayed from November to February (Fig. 1C). In February, the first birds migrated back to the Barents Sea (BS), and by March all birds had returned. In April, all birds were close to the breeding colony (Fig. 1D).

\section{CMR modeling of adult kittiwake survival}

The CMR analysis started with the Cormack-Jolly-Seber (CJS) model (Lebreton et al. 1992). All birds were captured only once, and attempts made to resight them in the following years. We, therefore, denote the recapture rate as resighting rate.

We assessed the goodness-of-fit (GOF) of the CJS model using U-CARE software (Choquet et al. 2009a). By doing so, we examined whether the model fitted the data and whether there was any heterogeneity in the resighting probabilities. This was done by evaluating the overdispersion coefficient, c-hat. Test 3.SR, a test component in the GOF test that tests the assumption that all marked individuals alive at time $i$ have the same probability of surviving to $i+1$ (transient effect), showed that there was a transient effect in the data $\mathbf{N}[0,1]=$ $-0.105, \mathrm{df}=13, \chi^{2}=87.98, p \approx 0$, c-hat $=$ 6.77), and test 2.CT, which tests the assumption of independence in the resighting rate (i.e. trap-happiness or trap-shyness) showed that there was trap-happiness in the data $(\mathrm{N}[0,1]=$ -23.40, $\mathrm{df}=19, \chi^{2}=677.09, p \approx 0$, c-hat $=$ 35.64). We, therefore, used the method proposed by Gimenez et al. (2003), who used a multi-state model, with 3 states, adding an unobservable state for nonresighted birds in the previous year (the probability of having not been seen before), to correct for heterogeneity in resighting probabilities (details in Reiertsen et al. 2012).
To estimate and compare the annual survival rates of adult kittiwakes, we used the program ESURGE (Choquet et al. 2009b). A time-dependent model was the starting point for the model selec-

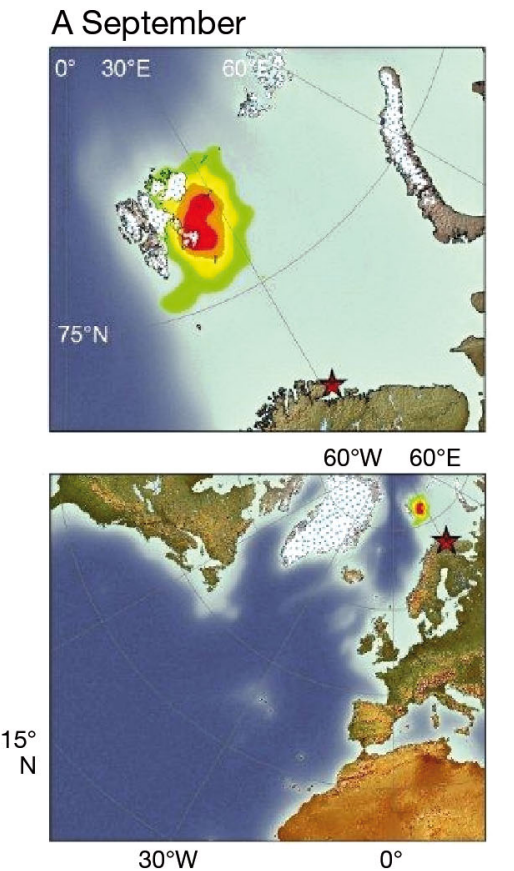

C December
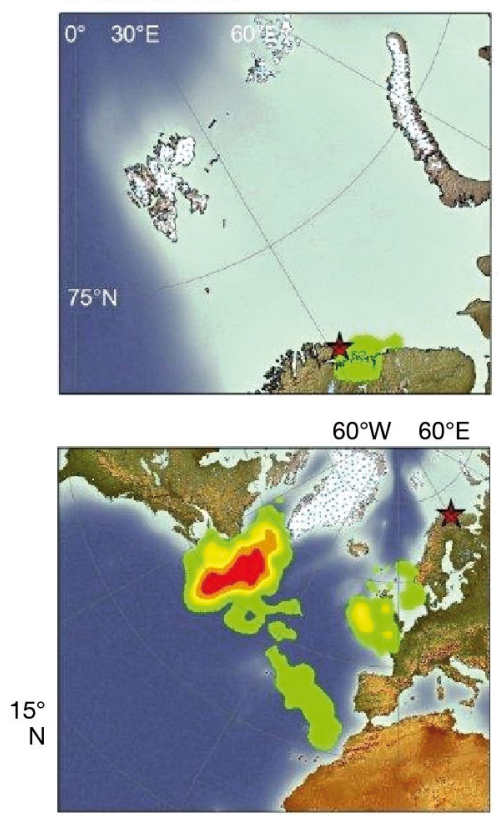

$30^{\circ} \mathrm{W}$ $0^{\circ}$
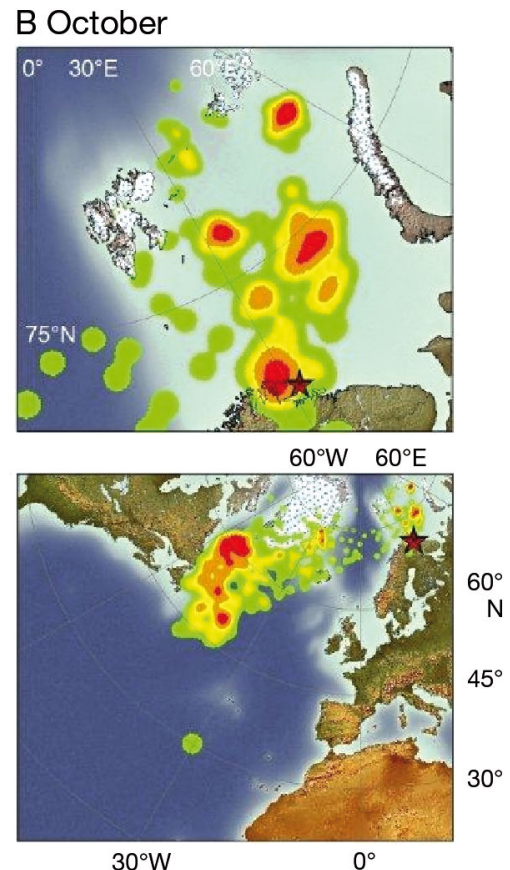

D April
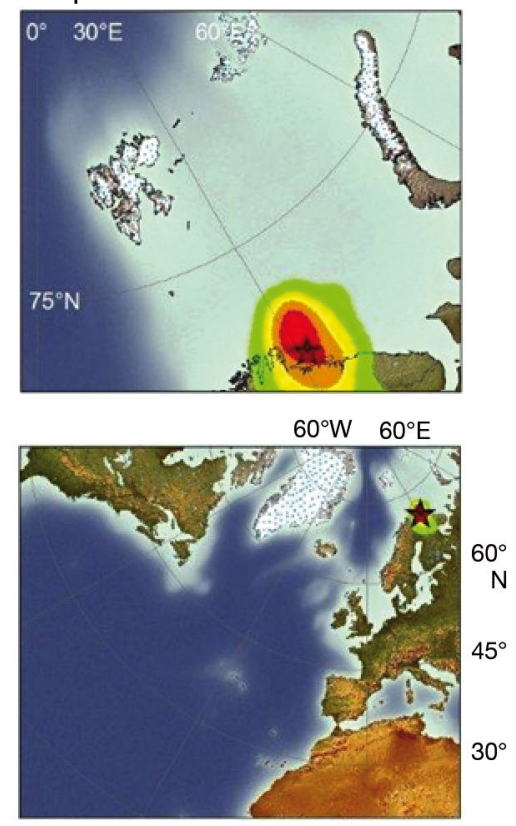

$30^{\circ} \mathrm{W}$ $0^{\circ}$

Fig. 1. Distribution of adult kittiwakes from Hornøya at different times of the year, as revealed by geolocators over 2 non-breeding seasons. The panels in the first row show an overview of the Barents Sea, and those in the second row show an overview of the North Atlantic including the Barents Sea. The 25, 50, 75 and $90 \%$ kernel contours (red, orange, yellow and green, respectively) are shown for the periods (A) 1-10 September, (B) 21-31 October, (C) 1-31 December and (D) 4-30 April. $\mathrm{n}=6$ (2008-2009), $\mathrm{n}=14$ (2009-2010) 

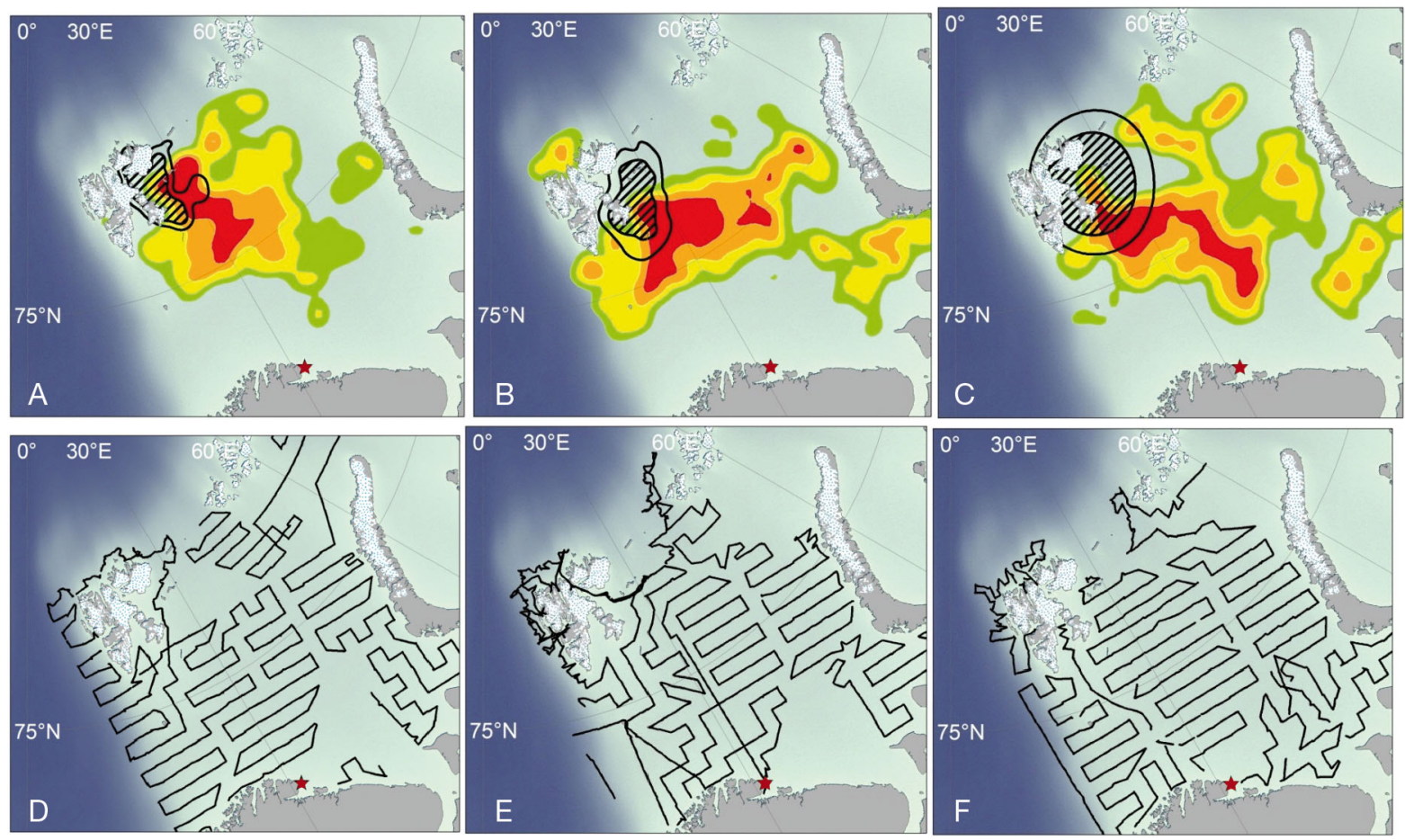

Fig. 2. Spatial distribution of capelin (coloured areas) and kittiwakes (black-contoured areas) in (A) 2008, (B) 2009 and (C) 2010. The data from $2008(n=6)$ and $2009(n=14)$ are based on light level geolocators, and the data from $2010(n=5)$ are based on satellite transmitters. The lower 3 panels show the survey areas of capelin between 20 and 30 August in (D) 2008, (E) 2009 and (F) 2010. Kernel contours for capelin are 25, 50, 75 and 90\% (red, orange, yellow and green, respectively) and for kittiwakes 50 and $75 \%$ (black; hatched and unhatched, respectively). Red stars: Hornøya

tion, denoted as $\operatorname{phi}(t) p(f+t)$, where phi was the annual adult survival and $p$ was the re-sighting probability, $t$ was time dependence and $f$ was the transition between states when we took into account trap-happiness in the model. By comparing the time-dependent model with the constant survival, denoted as phi $(i) p(f+t)$, the constant re-sighting model phi $(t) p(f)$, or both, phi(t)p(f), where $i$ denotes a constant model, we assessed the appropriate model for annual survival and re-sighting probability.

\section{Inclusion of covariates}

We included covariates in the models to examine whether they could explain the variation observed in the kittiwake adult survival rates. We started by including only one covariate at a time to assess the impact of each covariate on the survival rate, and then we extended the models using 2 covariates.

In wild populations, adult survival is most likely to be influenced by multiple factors (e.g. Burnham \& Anderson 2002), and models with full time variation usually provide the best description for rich data sets.
Finding a model with covariates that explain all the variation in survival is, therefore, unlikely, and residual unexplained variation after accounting for the effect of covariates can be expected (Grosbois et al. 2008). We assessed the ability of each covariate to describe significant variation in survival, using analysis of deviance tests (ANODEV: F-test statistic with $n_{\text {cov }}$ and $n-n_{\text {cov }}-1$ degrees of freedom, where $n_{\text {cov }}$ represents the number of covariates included and $n$ is the number of parameters of the time-dependent model) (Skalski et al. 1993, Grosbois et al. 2008, Lebreton et al. 2012), which is an established way of evaluating the significance of covariates. To assess the effect of the covariates on the kittiwake adult survival rate, we used an approximated $\mathrm{R}^{2}$ statistic, which compared the constant and the time-dependent survival models, which is done using the formula [Deviance (covariate model) - Deviance (constant model)]/[Deviance (time-dependent model) Deviance (constant model)] (Gaillard et al. 1997, Barbraud et al. 2000, Jenouvrier et al. 2006). This gives us the proportion of explained variation (Grosbois et al. 2008, Lebreton et al. 2012), which is denoted as $\mathrm{R}^{2}$ in Tables 1 \& S3 (in the Supplement at www.int-res. com/articles/suppl/m509p289_supp.pdf). 
Table 1. Overview of the most important models of kittiwake adult survival and their neighbouring models, with different environmental covariates. Phi is the survival rate and $p$ is the re-sighting rate. The notation $t$ indicates time-dependent, $f$ indicates the transition between 2 states and is a model where the re-sighting rate has been corrected for trap-happiness and transience, and $i$ indicates a constant model. The notations and explanations for the covariates are given in Table 2. Models are sorted by ascending QAIC ${ }_{c}$ (quasi-likelihood Akaike's information criterion corrected for small sample size and overdispersion) and $\triangle$ QAIC $_{c}$ (the difference between the QAIC $_{C}$ of a given model and the QAIC $_{C}$ of the best model) is given for covariate models only. QAIC ${ }_{c}$ wt: QAIC $_{c}$ weight. A total overview of the model selection is given in Table S3 in the Supplement (see www.int-res.com/articles/suppl/m509p289_supp.pdf)

\begin{tabular}{|c|c|c|c|c|c|c|c|c|}
\hline Model & $k$ & Deviance & $\mathrm{QAIC}_{\mathrm{C}}$ & $\Delta \mathrm{QAIC}_{\mathrm{c}}$ & $\mathrm{QAIC}_{\mathrm{c}} \mathrm{wt}$ & $F$ & $\mathrm{p}$ & $\mathrm{R}^{2}$ \\
\hline $\operatorname{phi}(t) p(f+t)$ & 42 & 10349.93 & 10434.58 & & & & & \\
\hline phi(CapelinTot+ThecoDec) $p(f+t)$ & 25 & 10405.13 & 10455.36 & 0 & 0.97 & 9.17 & 0.002 & 0.52 \\
\hline phi(CapelinTot+PcodEOS) $p(f+t)$ & 25 & 10412.01 & 10462.24 & 6.87 & 0.03 & 7.21 & 0.005 & 0.46 \\
\hline phi(CapelinTot+EuphDec) $p(f+t)$ & 25 & 10417.54 & 10467.77 & 12.41 & 0.00 & 5.93 & 0.01 & 0.41 \\
\hline phi(ThecoDec + PcodEOS $) p(f+t)$ & 25 & 10429.32 & 10479.55 & 24.19 & 0.00 & 3.78 & 0.041 & 0.31 \\
\hline phi(PcodEOS $) p(f+t)$ & 24 & 10432.47 & 10480.68 & 25.32 & 0.00 & 7.02 & 0.016 & 0.28 \\
\hline phi(CapelinTot) $p(f+t)$ & 24 & 10433.87 & 10482.08 & 26.71 & 0.00 & 6.61 & 0.019 & 0.27 \\
\hline phi(EuphDec) $p(f+t)$ & 24 & 10451.51 & 10499.72 & 44.36 & 0.00 & 2.33 & 0.143 & 0.11 \\
\hline phi(ThecoDec) $p(f+t)$ & 24 & 10458.36 & 10506.58 & 51.21 & 0.00 & 1.05 & 0.318 & 0.05 \\
\hline $\operatorname{phi}(i) p(f+t)$ & 23 & 10464.66 & 10510.86 & 55.49 & 0.00 & 0.00 & 0 & 0 \\
\hline
\end{tabular}

The model selection was performed using QAIC ${ }_{c}$ (quasi-likelihood Akaike's information criterion corrected for small sample size and overdispersion) (Burnham \& Anderson 2002), where the model with the lowest $\mathrm{QAIC}_{\mathrm{c}}$ value was considered the best. $\triangle \mathrm{QAIC}_{\mathrm{c}}$ is the difference between the $\mathrm{QAIC}_{\mathrm{c}}$ of a given model and the $\mathrm{QAIC}_{\mathrm{c}}$ of the best model. According to Burnham \& Anderson's (2002) scale of $\triangle$ QAIC $_{\mathrm{c}}$ model interpretation, models with scores of $\Delta$ QAIC $_{\mathrm{c}} \leq 2$ are strongly plausible, $4-7$ less plausible and $\geq 10$ improbable. Survival and resighting probability estimates are given with $95 \%$ confidence intervals. We also used model averaging to assess the effect of each covariate on adult survival rate. Model averaging provides an average weighted estimate of the covariates used in a given number of models (Burnham \& Anderson 2002).

A detailed description of how the covariates from the different areas and time periods were selected is given in the Supplement (see www.int-res.com/ articles/suppl/m509p289_supp.pdf), and a list of all the covariates used in the CMR analysis is given in Table 2. For EOS in the autumn, we used acoustic data of capelin (CapelinEOS) and polar cod (PcodEOS) from the yearly joint Norwegian-Russian ecosystem surveys as covariates (for a detailed description see Skern-Mauritzen et al. 2011). An overview of the survey area covered in 2008, 2009 and 2010 and the resulting capelin distribution is given in Fig. 2. The acoustic data of capelin used in the figures were log-transformed and are from 20 August to 30 September. Kernel contours (\%) were calculated and presented for capelin distribu- tion using the same method as described for kittiwakes (smoothing factor was $50 \mathrm{~km}$ ). We also used SST data (SSTautEOS), which were extracted from the Extended Reconstruction SST data set (available on a $2^{\circ} \times 2^{\circ}$ grid; Smith et al. 2008, NOAA 2012), for $\operatorname{EOS}\left(75^{\circ} \mathrm{N}, 80^{\circ} \mathrm{N}, 15^{\circ} \mathrm{E}\right.$ and $\left.35^{\circ} \mathrm{E}\right)$ during the postbreeding period (mean of August-September). For GBLS, we used data from the continuous plankton recorder survey (CPR data) from the winter period (November-February) from 1990 to 2010. The data were provided by the Sir Alister Hardy Foundation (SAHFOS) and consisted of monthly mean number of individuals of amphipods (Hyperiidea), euphausiids (Euphausiacea total), Calanus finmarchicus and pteropods (Thecosomata total). The area from which we extracted CPR data was within $40^{\circ} \mathrm{N}, 62^{\circ} \mathrm{N}$, $38^{\circ} \mathrm{W}$ and $60^{\circ} \mathrm{W}$. CPR methods are described in Lindley (1982). We also used SST from the same area in winter (mean of October-January) and the principal-component-based indices of the North Atlantic Oscillation (NAO) (NCARS 2012) as climatic covariates for this area and time period.

For the pre-breeding in BS, we used the data from ICES (2011) for the total biomass of capelin, (1-group) herring, and the eastern and the western distribution of polar cod in BS, which is defined as stock numbers of a given age on 1 January multiplied by weight at age and reflect the estimated densities of the fish species on 1 January. Additionally, for the area around Hornøya in the pre-breeding (monthly means of February-April) and breeding periods (means of May-July) (between $70^{\circ} \mathrm{N}, 72^{\circ} \mathrm{N}, 28^{\circ} \mathrm{E}$ and $34^{\circ} \mathrm{E}$ ) SST was used as climatic covariate. Average breeding 
Table 2. Overview of all covariates used in the capture-mark-resighting analysis with time periods and areas of interest. The notation used in the model selection is explained, and data sources are indicated. IMR: Norwegian Institute of Marine Research; NOAA: National Oceanic and Atmospheric Administration (USA); SAHFOS: Sir Alistair Hardy Foundation (UK); ICES: International Council for the Exploration of the Sea (Denmark)

\begin{tabular}{|c|c|c|c|c|}
\hline Time period & Area & $\begin{array}{l}\text { Covariate } \\
\text { notation }\end{array}$ & Covariate explanation & Source \\
\hline $\begin{array}{l}\text { Autumn } \\
\text { (Sep) }\end{array}$ & $\begin{array}{l}\text { East of Sval- } \\
\text { bard (EOS) }\end{array}$ & $\begin{array}{l}\text { CapelinEOS } \\
\text { PcodEOS } \\
\text { SSTautEOS }\end{array}$ & $\begin{array}{l}\text { Acoustic assessment of the capelin stock } \\
\text { Acoustic assessment of the polar cod stock } \\
\text { Sea surface temperature }\end{array}$ & $\begin{array}{l}\text { IMR } \\
\text { IMR } \\
\text { NOAA }\end{array}$ \\
\hline $\begin{array}{l}\text { Winter } \\
\text { (Nov-Dec) }\end{array}$ & $\begin{array}{l}\text { Grand Banks/ } \\
\text { Labrador Sea } \\
\text { (GBLS) }\end{array}$ & $\begin{array}{l}\text { ThecoDec } \\
\text { ThecoNov } \\
\text { HypDec } \\
\text { HypNov } \\
\text { EuphDec } \\
\text { EuphNov } \\
\text { CalDec } \\
\text { CalNov } \\
\text { SSTwinterGBLS }\end{array}$ & $\begin{array}{l}\text { Continously plankton recorded (CPR) } \\
\text { data of the suborder Thecosomata } \\
\text { CPR data of Thecosomata } \\
\text { CPR data of Hyperiidea } \\
\text { CPR data of Hyperiidea } \\
\text { CPR data of Euphausiacea } \\
\text { CPR data of Euphausiacea } \\
\text { CPR data of Calanus finmarchicus } \\
\text { CPR data of Calanus finmarchicus } \\
\text { Sea surface temperature }\end{array}$ & $\begin{array}{l}\text { SAHFOS } \\
\text { SAHFOS } \\
\text { SAHFOS } \\
\text { SAHFOS } \\
\text { SAHFOS } \\
\text { SAHFOS } \\
\text { SAHFOS } \\
\text { SAHFOS } \\
\text { NOAA }\end{array}$ \\
\hline $\begin{array}{l}\text { Winter } \\
\text { (Dec-Mar) }\end{array}$ & North Atlantic & NAOPC & $\begin{array}{l}\text { Principal component based indices of } \\
\text { the North Atlantic Oscillation }\end{array}$ & $\begin{array}{c}\text { NCARS } \\
(2012)\end{array}$ \\
\hline $\begin{array}{l}\text { Spring } \\
\text { (Mar-Apr) }\end{array}$ & $\begin{array}{l}\text { Barents Sea } \\
\text { (BS) }\end{array}$ & $\begin{array}{l}\text { CapelinTot } \\
\text { Herring1Y } \\
\text { PcodEast } \\
\text { PcodWest } \\
\text { SSTspringHorn }\end{array}$ & $\begin{array}{l}\text { Total biomass of capelin } \\
\text { 1-group herring } \\
\text { Total biomass of polar cod in the eastern } \\
\text { part of the Barents Sea } \\
\text { Total biomass of polar cod in the western } \\
\text { parts of the Barents Sea } \\
\text { Sea surface temperature }\end{array}$ & $\begin{array}{l}\text { ICES } \\
\text { ICES } \\
\text { ICES }\end{array}$ \\
\hline $\begin{array}{l}\text { Summer } \\
\text { (breeding season) }\end{array}$ & $\begin{array}{l}\text { Around } \\
\text { Hornøya }\end{array}$ & $\begin{array}{l}\text { SSTsummerHorn } \\
\text { BSL1 }\end{array}$ & $\begin{array}{l}\text { Sea surface temperature } \\
\text { Breeding success, lagged } 1 \mathrm{yr}\end{array}$ & NOAA \\
\hline
\end{tabular}

success in the previous year (BSL1) was also used as a population-level covariate for the breeding season.

Some of the covariates had missing values for some years. These included Calanus finnmarchicus, Hyperiidea, Euphausiacea and Thecosomata in December 1991. To obtain a complete time series, we used the method developed by Colebrook (1975), which multiplies the long-term monthly mean corresponding to a missing month in a given year by the ratio of the sum of the non-missing values in that year to the sum of the corresponding long-term monthly means. Fish and plankton covariates were log-transformed prior to analysis to achieve a linear relationship on a log scale.

Covariates with linear temporal trends were detrended, using the residuals from the regression between the parameter and the year (Table S2 in the Supplement). All covariates were checked for autocorrelation after detrending (see Table S1 and Fig. S1 in the Supplement for an overview of colinearities between and temporal variation in the covariates), and we did not enter covariates with high correlation in the same model (Table S1 in the Supplement). Significant autocorrelation $(p<0.05)$ was when $R \geq 0.44$.

\section{RESULTS}

An overview of the best models in the model selection and their neighbouring models is given in Table 1, and a total overview of the model selection is given in Table S3 in the Supplement.

Overall, the model with the lowest QAIC $_{\mathrm{C}}$ (Table 1) was the model with time dependency in both the survival rate and the resighting rate, where we had corrected for transience and trap-happiness (Fig. 3). Survival varied extensively with time (mean phi $=0.85$, range $=0.66-0.98$ ). There were 2 severe drops in the survival rate; one in 1994 (phi $=0.66, \mathrm{SE}=0.05$ ) and one in 2003 (phi = 0.74, SE =0.04; Fig. 3). Models corrected for trap-happiness were clearly better (lower $\Delta \mathrm{AIC}_{\mathrm{c}}$ ) than models without such a correction (Table S3 in the Supplement).

None of the models with covariates improved the model with full time-dependency of both the survival probability and the re-sighting rate, because of the presence of residual unexplained variation as explained in the methods. We, therefore, only compared the difference between the QAIC $_{C}$ values $\left(\Delta \mathrm{QAIC}_{\mathrm{c}}\right)$ for models that included covariates. 


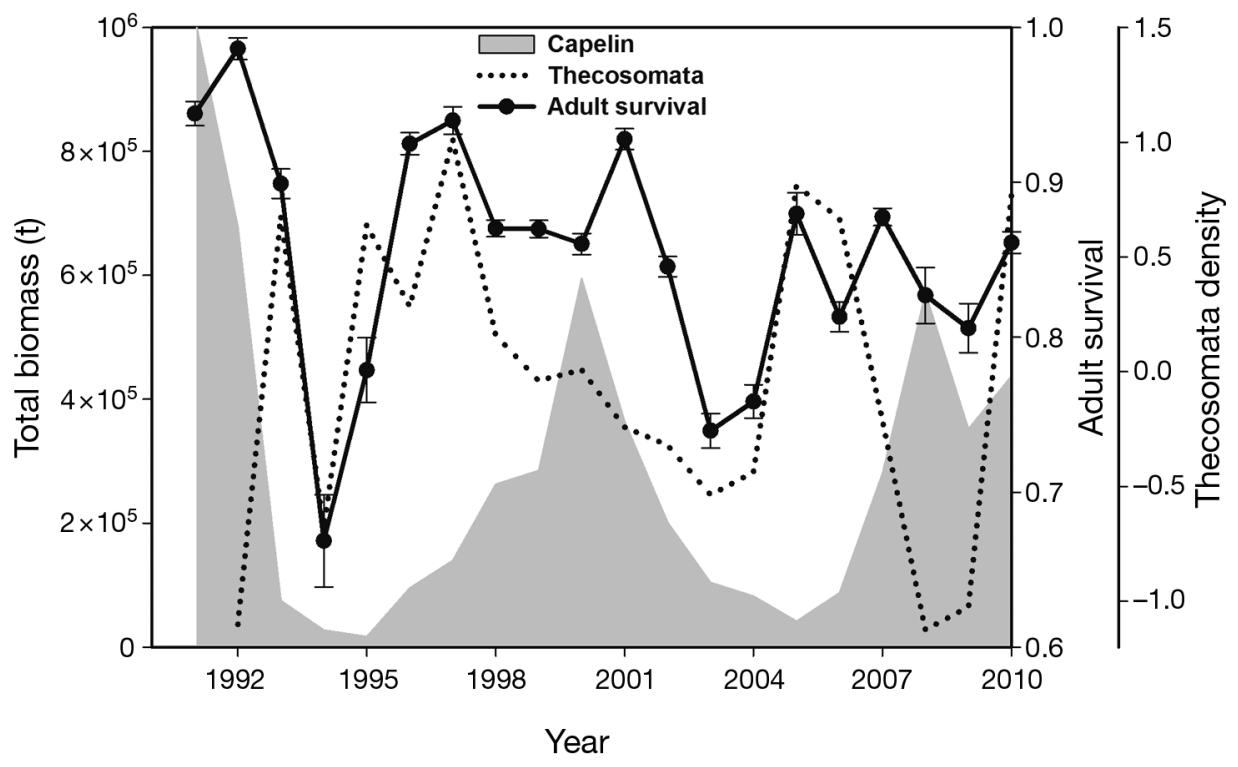

Fig. 3. Temporal variation of kittiwake adult survival rates (solid line; error bars are $\pm 95 \%$ confidence limits) and the best covariates, total biomass of capelin in the Barents Sea (grey area) and detrended Thecosomata density (monthly mean no. of ind. for specified area; see 'Materials and methods') in December in the Grand Banks/ Labrador Sea area (dotted line) between 1990 and 2010
Among the covariate models, the model that included temporal variation of the total biomass of capelin in BS (CapelinTot) and the temporal variation of Thecosomata density in December in the GBLS (ThecoDec) was clearly the best $\left(\mathrm{QAIC}_{\mathrm{c}}\right.$ weight $=$ 0.97; Table 1). This model was $6.87 \Delta \mathrm{QAIC}_{\mathrm{c}}$ units better than the second best covariate model that included the total biomass of capelin in BS and the acoustic data of polar cod in EOS (PcodEOS) $\left(\right.$ QAIC $_{c}$ weight $=0.03$; Table 1 ). Model averaging of the 3 covariates included in these models gives estimates of $0.40,0.50$ and -0.008 for CapelinTot, ThecoDec and PcodEOS, respectively. The effect of both Thecosomata in GBLS in December and the total biomass of capelin in BS on adult kittiwake survival are thus very strong compared with polar cod in EOS in the post-breeding period. Estimates of the covariates from the top model explaining adult survival were both positive $(0.41$ [range $=0.30-0.52$ ] and 0.52 [range $=0.33-0.70]$ for CapelinTot and ThecoDec with $95 \%$ confidence intervals). The temporal trends in both the time-dependent model and the best covariate model are shown in Fig. 4.

When considering models with single covariates, they all had a very high $\mathrm{QAIC}_{\mathrm{C}}$ and $\mathrm{QAIC}_{\mathrm{c}}$ weights were very close to zero. Thus models with 2 covariates were clearly better than single-covariate models (Table 1). The best single-covariate model was the one with acoustic data of polar cod in EOS, which explained $28 \%$ of the variation in adult survival but was $26.32 \Delta \mathrm{QAIC}_{\mathrm{c}}$ units higher than the overall best covariate model (Table 1). Capelin in BS and the density of Thecosomata in GBLS were

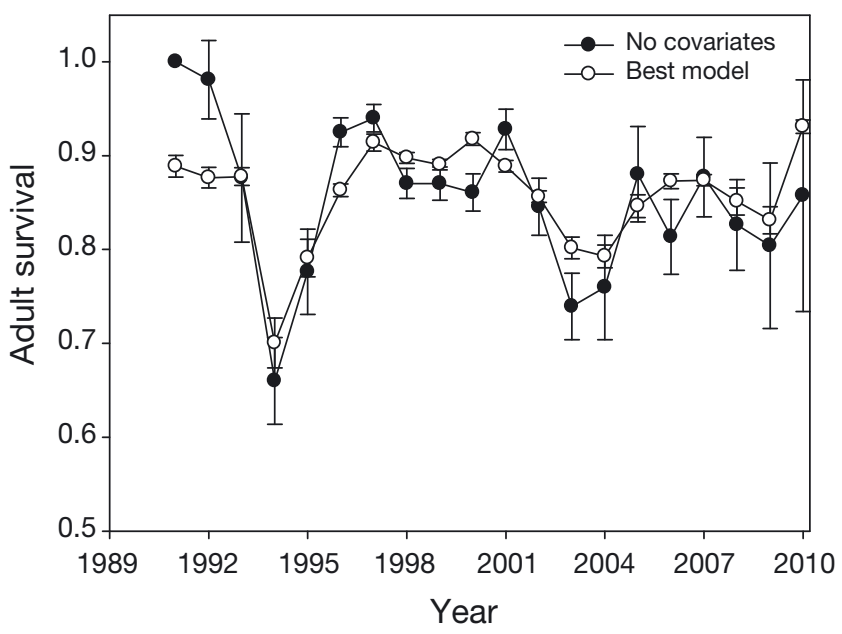

Fig. 4. Temporal variation in kittiwake adult survival from the time-dependent model with no covariates $(\bullet)$ and the model with total biomass of capelin in the Barents Sea and Thecosomata in the Grand Banks/Labrador Sea in December (O) between 1991 and 2010

26.71 and $51.21 \Delta \mathrm{QAIC}_{\mathrm{c}}$ units higher, respectively, than the overall best covariate model (Table 1). None of the models that included climatic covariates was ever better than models including prey densities. The best climatic model included ThecoDec and SST in EOS in the post-breeding season $\left(\right.$ SSTautEOS) $\left(\triangle\right.$ QAIC $_{\mathrm{c}}=22.48, \mathrm{R}^{2}=0.32$; Table S3 in the Supplement). The models including covariates from the breeding season had a much higher $\mathrm{QAIC}_{\mathrm{c}}$ than the best covariate models $\left(\triangle \mathrm{QAIC} \mathrm{C}_{\mathrm{C}}=\right.$ 55.19 and 56.71, $\mathrm{R}^{2}=0.02$ and 0.01 , for SSTsummerHorn and BSL1, respectively). 


\section{DISCUSSION}

The best covariate model explaining the temporal variation of kittiwake adult survival included the total biomass of capelin in the BS and the monthly mean density of Thecosomata in GBLS in December. This suggests that prey densities in the BS and the GBLS area, which both seem to be important nonbreeding areas for kittiwakes from Hornøya (and many other kittiwake populations, e.g. Bogdanova et al. 2011, Frederiksen et al. 2012), affect adult survival of kittiwakes.

\section{Capelin in the Barents Sea}

Capelin is one of the most abundant fish species in the BS (Orlova et al. 2010), and the stocks fluctuate greatly (Ushakov \& Ozhigin 1987). During the period of the present study, the capelin stock collapsed twice (around 1994 and 2003) (Gjøsæter et al. 2009), and both collapses coincided with a corresponding drop in the adult survival rate of kittiwakes (Fig. 2). The collapse in 2003 was accompanied by an exceptional die-off of adult birds in the region in early spring (Barrett et al. 2004). Capelin plays a key role in the pelagic ecosystem of the Barents Sea (Orlova et al. 2010) and follows a characteristic seasonal migration pattern (Fauchald et al. 2006, Gjøsæter et al. 2011). It is an important grazer of zooplankton (Hassel et al. 1991, Gjøsæter et al. 2002, Stige et al. 2009) and an important food source for Atlantic cod Gadus morhua, seabirds and marine mammals (Folkow et al. 2000, Nilssen et al. 2000, Bogstad \& Gjøsæter 2001, Fauchald et al. 2011).

In general, kittiwakes are known to feed on schooling fish (Lewis et al. 2001, Carscadden et al. 2002), and in the southwest BS (Hornøya), capelin is the main prey during the breeding season (Furness \& Barrett 1985, Barrett 2007). It has also been shown that kittiwake breeding success on Hornøya decreases when the abundance of capelin is low (Barrett 2007, A. Ponchon et al. unpubl.). Although we do not know in detail the diet of kittiwakes during the non-breeding season, the results of this study and those of Barrett et al. (2004) show that the temporal variation in the BS capelin stock may have a strong impact on the yearly variation in kittiwake survival rates. Kittiwakes from Hornøya stay in the BS from March to October, i.e. the pre-breeding season, the breeding season and post-breeding season, when they move to EOS. It is likely that the capelin densities in the BS when the kittiwakes return in March-
April are critical for their survival. This return coincides with the capelin spawning migration towards the coast of Norway and Russia in March-April (Gjøsæter et al. 2011), a time when the fish are full of energy-rich gonads (Montevecchi \& Piatt 1984). In the pre-breeding season, the northern BS is still covered with ice and primary production is low, such that the seabirds are constrained to feed on mainly pelagic fish such as 1-group herring and capelin (Fauchald et al. 2011). The capelin spawning migration is highly concentrated in space and time (Fauchald et al. 2011), and it is very likely that kittiwakes are especially sensitive to the abundance and distribution of this energy-packed fish at this time of the year, since they need to build energy reserves prior to reproduction.

After the breeding season, the kittiwakes move quickly to EOS (Figs. 1A \& 4C). Capelin distributions in the post-breeding period show a limited overlap with the kittiwake distribution (Fig. 4). Acoustic data of capelin and polar cod from this area in this time period did not, however, correlate with kittiwake survival, which suggests that kittiwakes find other prey, e.g. zooplankton in EOS in the post-breeding period, as also suggested by González-Solís et al. (2011). Unfortunately, there are no temporal plankton data from EOS that could have been used to test directly whether conditions from this area also were important for kittiwake survival. Another implication is that capelin seems to have the highest impact on kittiwake survival during the pre-breeding and/or breeding season.

\section{Thecosomata in the GBLS}

The other prey covariate which entered the toprank model was the density of Thecosomata in GBLS in December, a time when most of the kittiwakes from Hornøya were present in that area. There is some earlier evidence that kittiwakes feed at lower trophic levels in winter and that they probably feed more on a variety of large zooplankton species, such as amphipods, pteropods and euphausiids (Mehlum \& Gabrielsen 1993, Karnovsky et al. 2008, GonzálezSolís et al. 2011, Frederiksen et al. 2012), than in the breeding season when their main prey is fish (e.g. Lewis et al. 2001, Carscadden et al. 2002, Barrett 2007, A. Ponchon et al. unpubl.). Furthermore, Karnovsky et al.'s (2008) study from the North Water Polynya showed that kittiwakes there fed extensively on the pteropod Limacina helicina and that they had fatty acid signatures resembling the signatures of the 
little auks Alle alle that feed exclusively on zooplankton (Karnovsky et al. 2008). This supports our hypothesis that Thecosomata is a likely food for kittiwakes.

Thecosomata is a taxon of pelagic swimming sea snails also called sea butterflies or pteropods. They are rich in lipids, live their whole life in a planktonic form, and can be found in large concentrations in the upper layer of the water. They play an important role in the marine food web, in particular at high latitudes (Comeau et al. 2012), and are important food sources for herring and capelin and for higher predators, such as whales and seabirds (Hunt et al. 2008, Orlova et al. 2011, Comeau et al. 2012). The density of Thecosomata in December declined steeply between 1990 and 2011 (Fig. 2), possibly as a result of ocean acidification (Lischka et al. 2011). Thecosomata, such as Limacina helicina, have an aragonitic shell, which makes them particularly sensitive to acidification, a process that is expected to be most serious in Arctic oceans (Steinacher et al. 2009, Comeau et al. 2012) and which will be more severe when ocean temperatures increase (Lischka et al. 2011). Kittiwakes from most of the breeding colonies in the north Atlantic spend their winter in this area (Frederiksen et al. 2012); hence, the steep decline in Thecosomata abundances could be an important driver of the overall decline in the North Atlantic kittiwake populations.

\section{SST}

Since both the temporal and spatial variance in SST may influence the distribution of prey independent of total density, we used un-lagged SST from the different areas and time periods together with prey category data in the models but found no apparent direct effects of SST. Although kittiwakes are very sensitive to changes in the marine system, they are also highly mobile, especially in the non-breeding period, when they are not constrained by the need to return regularly to the colony and can easily move around searching for available food (Fauchald 1999, Pinaud \& Weimerskirch 2005, Certain et al. 2011). This could indicate that kittiwakes are more sensitive to overall prey density as such and not to small-scale changes in the spatial distribution of prey linked to oceanographic changes. Increasing SST, however, could also result in a vertical shift of preys in the water masses (i.e. prey move to deeper and colder water), thus making them inaccessible to kittiwakes that cannot dive, even if prey densities are high.

None of the models that included any climatic covariates (SST and NAO) could compete with the best models in the model selection. This may indicate that kittiwakes are not directly affected by the climate factors in these areas and that their abilities to move around may buffer this effect. Additionally, this may give some support to the explanation that kittiwakes are more sensitive to overall prey densities in these areas than to the spatial changes of the prey.

None of the breeding-season covariates (i.e. breeding success or SST in the summer near the colony) could explain any temporal variability in adult survival, which is in contrast to other studies (Oro \& Furness 2002, Frederiksen et al. 2004). However, as stressed by Frederiksen et al. (2004), identifying factors outside the breeding season was very difficult at that time because of the limited knowledge of kittiwakes' non-breeding distribution, and the importance of the conditions in the non-breeding areas could not be ruled out as an explanation of the adult survival variability.

\section{CONCLUSIONS}

This study demonstrates the importance of linking the knowledge of the winter distribution of seabirds and density of the prey they feed on in their wintering areas to temporal variation of adult survival rates. Although it has been suggested that adult survival may be primarily influenced by prey densities and oceanographic conditions in the wintering area (Gaston 2003, Daunt et al. 2006, Wanless et al. 2007, Frederiksen et al. 2008a, Harris et al. 2010), lack of data on migration patterns and the whereabouts of important wintering areas has precluded the search for causal explanations. This study is among the first to examine the influence of prey densities in nonbreeding areas on the survival of seabirds. The study is highly exploratory and based on scarce loggerhead data, but it suggests that Thecosomata in the GBLS and capelin in the BS are important prey species for kittiwakes in the non-breeding season. This needs to be tested further. Both the BS and the GBLS are impacted by intense anthropogenic activities, such as fisheries, international shipping and the offshore oil and gas industry, with several reports of operational and accidental discharges of hydrocarbons (Hedd et al. 2011). All these activities pose risks to seabirds, and the knowledge of how important these areas are to a species that is globally declining has strong implications for conservation and management of both these areas.

The migration part of our study is based on only $3 \mathrm{yr}$ of data and a rather low number of tracked 
individuals. There is therefore a strong need for a larger sample of logger data over more years to examine the stability and evidence of winter migration patterns. However, although the sample size from Hornøya is small, there is evidence that birds from several populations return to the same areas in different years (Frederiksen et al. 2012, B. Moe et al. unpubl., A. Ponchon et al. unpubl.). Also, the time series of CMR data is $22 \mathrm{yr}$ long, and since we found such strong correlations between the survival rate and the covariates from the main areas revealed by migration data, it is plausible that there is some stability in the migration pattern. A challenge for future studies of demography and causal mechanisms will be to map both the stability of wintering areas over time and not only the density of prey, but also the spatial distribution of the prey in different areas. Such information is essential for the conservation and management of any seabird, including the kittiwake, a species that is declining globally.

Acknowledgements. We thank all the fieldworkers who have read colour rings over the years. The Norwegian Coastal Administration is thanked for the use of the lighthouse on Hornøya as a base for the fieldwork. This study was funded by the University of Tromsø and the Norwegian Directorate for Nature Management. Since 2005, the study has also been financed through the Norwegian Seabird Program (SEAPOP). The work was also partly supported by programme no. 333 of the French Polar Institute (IPEV) and the Norwegian Research Council (project no. 216547/E40 to K.E.E.). We also thank Marit Reigstad for valuable input on the ecological importance of the hot spot area east of Svalbard, and Karen McCoy and Victor Garcia Matarrantz for help in the field. We acknowledge comments from 2 anonymous referees that helped improve this article.

\section{LITERATURE CITED}

Barbraud C, Weimerskirch H, Guinet C, Jouventin P (2000) Effect of sea-ice extent on adult survival of an Antarctic top predator: the snow petrel Pagodroma nivea. Oecologia 125:483-488

Barrett RT (2007) Food web interactions in the southwestern Barents Sea: black-legged kittiwakes Rissa tridactyla respond negatively to an increase in herring Clupea harengus. Mar Ecol Prog Ser 349:269-276

Barrett RT (2010) Kittiwake longevity record for Norway. Seab Group Newsl 113:6

Barrett RT, Josefsen TD, Polder A (2004) Early spring wreck of black-legged kittiwakes Rissa tridactyla in North Norway, April 2003. Atl Seab 6:33-45

Barrett RT, Lorentsen SH, Anker-Nilssen T (2006) The status of breeding seabirds in mainland Norway. Atl Seab 8: 97-126

Beyer HL (2004) Hawth's analysis tools for ArcGIS. Avail- able at www.spatialecology.com/htools

Bogstad B, Gjøsæter H (2001) Predation by cod (Gadus morhua) on capelin (Mallotus villosus) in the Barents Sea: implications for capelin stock assessment. Fish Res 53:197-209

Burnham KP, Anderson DR (2002) Model selection and multimodel inference: a practical information-theoretic approach, 2nd edn. Springer, New York, NY

Cairns DK (1992) Bridging the gap between ornithology and fisheries science: use of seabird data in stock assessment models. Condor 94:811-824

Carscadden JE, Montevecchi WA, Davoren GK, Nakashima BS (2002) Trophic relationships among capelin (Mallotus villosus) and seabirds in a changing ecosystem. ICES J Mar Sci 59:1027-1033

Certain G, Masse J, Van Canneyt O, Petitgas P, Doremus G, Santos MB, Ridoux V (2011) Investigating the coupling between small pelagic fish and marine top-predators using data collected from ecosystem-based surveys. Mar Ecol Prog Ser 422:23-39

Choquet R, Lebreton JD, Gimenez O, Reboulet AM, Pradel R (2009a) U-CARE: utilities for performing goodness of fit tests and manipulating CApture-REcapture data. Ecography 32:1071-1074

Choquet R, Rouan L, Pradel R (2009b) Program ESURGE: a software application for fitting multievent models. In: Thomson DL, Cooch EG, Conroy MJ (eds) Modeling demographic processes in marked populations. Springer, New York, NY, p 845-865

Colebrook JM (1975) The continuous plankton recorder survey: automatic data processing methods. Bull Mar Ecol 8: 123-142

> Comeau S, Gattuso JP, Nisumaa AM, Orr J (2012) Impact of aragonite saturation state changes on migratory pteropods. Proc Biol Sci 279:732-738

Coulson JC (2011) The kittiwake. T \& AD Poyser, London

- Croxall JP, Butchart SHM, Lascelles B, Stattersfield AJ, Sullivan B, Symes A, Taylor P (2012) Seabirds conservation status, threats and priority actions: a global assessment. Bird Conserv Int 22:1-34

Cury PM, Boyd IL, Bonhommeau S, Anker-Nilssen T and others (2011) Global seabird response to forage fish depletion - one third for the birds. Science 334:1703-1706

Daunt F, Afanasyev V, Silk JRD, Wanless S (2006) Extrinsic and intrinsic determinants of winter foraging and breeding phenology in a temperate seabird. Behav Ecol Sociobiol 59:381-388

> Durant JM, Hjermann DØ, Anker-Nilssen T, Beaugrand G, Mysterud A, Pettorelli N, Stenseth NC (2005) Timing and abundance as key mechanisms affecting trophic interactions in variable environments. Ecol Lett 8:952-958

- Egevang C, Stenhouse IJ, Phillips RA, Petersen A, Fox JW, Silk JRD (2010) Tracking of Arctic terns Sterna paradisaea reveals longest animal migration. Proc Natl Acad Sci USA 107:2078-2081

- Erikstad KE (1990) Winter diets of four seabird species in the Barents Sea after a crash in the capelin stock. Polar Biol 10:619-627

Erikstad KE, Reiertsen TK, Barrett RT, Vikebø F, Sandvik H (2013) Seabird-fish interactions: the fall and rise of a common guillemot population. Mar Ecol Prog Ser 475: $267-276$

> Fauchald P (1999) Foraging in a hierarchical patch system. Am Nat 153:603-613

Fauchald P, Mauritzen M, Gjøsæter H (2006) Density- 
dependent migratory waves in the pelagic ecosystem. Ecology 87:2915-2924

Fauchald P, Zibyanov SV, Strøm H, Barrett RT (2011) Seabirds. In: Jakobsen T, Ozhigin VK (eds) The Barents Sea. Ecosystem, resources and management. Half a century of Russian-Norwegian cooperation. Tapir Academic Press, Trondheim, p 373-394

Folkow LP, Haug T, Nilssen KT, Nordøy ES (2000) Estimated food consumption of minke whales (Balaenoptera acutirostrata) in northeast Atlantic waters in 1992-1995. NAMMCO Sci Publ 2:65-80

Frederiksen M (2010) Appendix 1: Seabirds in the North East Atlantic. A review of status, trends and anthropogenic impact. TemaNord 587:47-122

Frederiksen M, Wanless S, Harris MP, Rothery P, Wilson LJ (2004) The role of industrial fisheries and oceanographic change in the decline of North Sea black-legged kittiwakes. J Appl Ecol 41:1129-1139

Frederiksen M, Daunt F, Harris MP, Wanless S (2008a) The demographic impact of extreme events: stochastic weather drives survival and population dynamics in a long-lived seabird. J Anim Ecol 77:1020-1029

> Frederiksen M, Jensen H, Daunt F, Mavor RA, Wanless S (2008b) Differential effects of a local industrial sand lance fishery on seabird breeding performance. Ecol Appl 18:701-710

> Frederiksen M, Moe B, Daunt F, Phillips RA and others (2012) Multi-colony tracking reveals the non-breeding distribution of a pelagic seabird on an ocean basin scale. Divers Distrib 18:530-542

Furness RW (2003) Impacts of fisheries on seabird communities. Sci Mar 67:33-45

- Furness RW, Barrett RT (1985) The food requirements and ecological relationships of a seabird community in north Norway. Ornis Scand 16:305-315

Furness RW, Tasker ML (2000) Seabird-fishery interactions: quantifying the sensitivity of seabirds to reductions in sandeel abundance, and identification of key areas for sensitive seabirds in the North Sea. Mar Ecol Prog Ser 202:253-264

Gaillard JM, Boutin JM, Delorme D, Van Laere G, Duncan P, Lebreton JD (1997) Early survival in roe deer: causes and consequences of cohort variation in two contrasted populations. Oecologia 112:502-513

Gaston AJ (2003) Synchronous fluctuations of thick-billed murre (Uria lomvia) colonies in the Eastern Canadian Arctic suggest population regulation in winter. Auk 120: 362-370

Gimenez O, Choquet R, Lebreton JD (2003) Parameter redundancy in multistate capture recapture models. Biom J 45:704-722

Gjøsæeter H, Dalpadado P, Hassel A (2002) Growth of Barents Sea capelin (Mallotus villosus) in relation to zooplankton abundance. ICES J Mar Sci 59:959-967

Gjøsæter H, Bogstad B, Tjelmeland S (2009) Ecosystem effects of the three capelin stock collapses in the Barents Sea. Mar Biol Res 5:40-53

Gjøsæter H, Ushakov NG, Prozorkevich DV (2011) Capelin. In: Jakobsen T, Ozhigin VK (eds) The Barents Sea. Ecosystem, resources, management. Half a century of Russian-Norwegian cooperation. Tapir Academic Press, Trondheim, p 201-214

Godø OR (2003) Fluctuation in stock properties of north-east Arctic cod related to long-term environmental changes. Fish Fish 4:121-137
Golet GH, Irons DB, Estes JA (1998) Survival costs of chick rearing in black-legged kittiwakes. J Anim Ecol 67: $827-841$

> González-Solís J, Croxall JP, Oro D, Ruiz X (2007) Transequatorial migration and mixing in the wintering areas of a pelagic seabird. Front Ecol Environ 5:297-301

> González-Solís J, Smyrli M, Militão T, Gremillet D, Tveraa T, Phillips RA, Boulinier T (2011) Combining stable isotope analyses and geolocation to reveal kittiwake migration. Mar Ecol Prog Ser 435:251-261

Grebmeier JM, Overland JE, Moore SE, Farley EV and others (2006) A major ecosystem shift in the Northern Bering Sea. Science 311:1461-1464

- Grosbois V, Gimenez O, Gaillard JM, Pradel R and others (2008) Assessing the impact of climate variation on survival in vertebrate populations. Biol Rev Camb Philos Soc 83:357-399

> Guilford T, Meade J, Willis RA, Phillips D and others (2009) Migration and stopover in a small pelagic seabird, the Manx shearwater Puffinus puffinus: insights from machine learning. Proc Biol Sci 276:1215-1223

> Harris MP, Anker-Nilssen T, McCleery RH, Erikstad KE, Shaw N, Grosbois V (2005) Effect of wintering area and climate on the survival of adult Atlantic puffins Fratercula arctica in the eastern Atlantic. Mar Ecol Prog Ser 297:283-296

> Harris MP, Daunt F, Newell FM, Phillips RA, Wanless S (2010) Wintering areas of adult Atlantic puffins Fratercula arctica from a North Sea colony as revealed by geolocation technology. Mar Biol 157:827-836

Harrison XA, Blount JD, Inger R, Norris DR, Bearhop S (2011) Carry-over effects as drivers of fitness differences in animals. J Anim Ecol 80:4-18

Hassel A, Skjoldal HR, Gjøsæte H, Loeng H, Omli L (1991) Distribution and life history of krill from the Barents Sea. In: Sakshaug E, Hopkins CCE, Øritsland NA (eds) Proceedings of the Pro Mare Symposium on Polar Marine Ecology. Trondheim, Norway, p 371-288

Hedd A, Montevecchi WA, McFarlane L, Tranquilla CM and others (2011) Reducing uncertainty on the Grand Bank: tracking and vessel surveys indicate mortality risks for common murres in the North-West Atlantic. Anim Conserv 14:630-641

Hunt B, Pakhomov E, Hosie G, Siegel V, Ward P, Bernard K (2008) Pteropods in southern Ocean ecosystems. Prog Oceanogr 78:193-221

ICES (International Council for the Exploration of the Sea) (2011) Report of the Arctic Fisheries Working Group (AFWG). ICES CM 2011/ACOM:05. ICES, Copenhagen

> Jenouvrier S, Barbraud C, Weimerskirch H (2005) Longterm contrasted responses to climate of two Antarctic seabird species. Ecology 86:2889-2903

> Jenouvrier S, Barbraud C, Weimerskirch H (2006) Sea ice affects the population dynamics of Adélie penguins in Terre Adélie. Polar Biol 29:413-423

Kålås JA, Viken A, Henriksen S, Skjelseth S (2010) The 2010 Norwegian red list for species. Norwegian Biodiversity Centre, Trondheim

Karnovsky NJ, Hobson KA, Iverson S, Hunt GL Jr (2008) Seasonal changes in diets of seabirds in the North Water Polynya: a multiple-indicator approach. Mar Ecol Prog Ser 357:291-299

Lack D (1968) Ecological adaptations for breeding in birds. Methuen, London

Le Bohec C, Durant JM, Gauthier-Clerc M, Stenseth NC and 
others (2008) King penguin population threatened by Southern Ocean warming. Proc Natl Acad Sci USA 105: 2493-2497

Lebreton JD, Clobert J (1991) Bird population dynamics, management and conservation: the role of mathematical modelling. In: Perrins CM, Lebreton JD, Hiron GJM (eds) Bird population studies: relevance to conservation and management. Oxford University Press, Oxford, p 105-125

Lebreton JD, Burnham KP, Clobert J, Anderson D (1992) Modeling survival and testing biological hypotheses using marked animals: a unified approach with case studies. Ecol Monogr 62:67-118

Lebreton JD, Choquet R, Gimenez O (2012) Simple estimation and test procedures in capture-mark-recapture mixed models. Biometrics 68:494-503

Lewis S, Wanless S, Wright PJ, Harris MP, Bull J, Elston DA (2001) Diet and breeding performance of black-legged kittiwakes Rissa tridactyla at a North Sea colony. Mar Ecol Prog Ser 221:277-284

> Lewison R, Oro D, Godley BJ, Underhill L, Bearhop S and others (2012) Research priorities for seabirds: improving conservation and management in the 21st century. Endang Species Res 17:93-121

Lindley JA (1982) Continous plankton records: geographical variations in numerical abundance, biomass and production of euphausiids in the North Atlantic Ocean and the North Sea. Mar Biol 71:7-10

Lischka S, Buedenbender J, Boxhammer T, Riebesell U (2011) Impact of ocean acidification and elevated temperatures on early juveniles of the polar shelled pteropod Limacina helicina: mortality, shell degradation, and shell growth. Biogeosci Discuss 7:8177-8214

Lydersen C, Giertz I, Weslawski JM (1989) Stomach contents of autumn-feeding marine vertebrates from Hornsund, Svalbard. Polar Res 25:107-114

Mehlum F, Gabrielsen GW (1993) The diet of high-arctic seabirds in coastal and ice-covered, pelagic areas near the Svalbard archipelago. Polar Res 12:1-20

Montevecchi WA, Piatt J (1984) Composition and energy contents of mature inshore spawning capelin (Mallotus villosus): implications for seabird predators. Comp Biochem Physiol A 78:15-20

NCARS (National Center for Atmospheric Research Staff) (eds) (2012) The climate data guide: Hurrell North Atlantic Oscillation (NAO) index (PC based). Available at https://climatedataguide.ucar.edu/guidance/hurrellnorth-atlantic-oscillation-nao-index-pc-based

Nilssen KT, Pedersen OP, Folkow LP, Haug T (2000) Food consumption estimates of Barents Sea harp seals. In: Vikingsson GK, Kapel FO (eds). Minke whales, harp seals and hooded seals: major predators in the North Atlantic ecosystem, Vol 2. NAMMCO Scientific Publications, Tromsø, p 9-27

NOAA (National Oceanic and Atmospheric Administration) (2012) NOAA NCDC Extended Reconstructed Sea Surface Temperature Dataset, Version3b. Available at http://iridl.ldeo.columbia.edu/SOURCES/.NOAA/.NCDC/. ERSST/.version3b/ (accessed 22 February 2012)

> Orlova EL, Rudneva GB, Renaud PE, Eiane K, Savinov V, Yurko AS (2010) Climate impacts on feeding and condition of capelin Mallotus villosus in the Barents Sea: evidence and mechanisms from a 30 year data set. Aquat Biol 10:105-118

Orlova EL, Dalpadado P, Knutsen T, Nesterova VN,
Prokopchuk IP (2011) Zooplankton. In: Jakobsen, T, Ozhigin VK (eds) The Barents Sea. Ecosystem resources management. Half a century of RussianNorwegian cooperation. Tapir Academic Press, Trondheim, p 91-119

Oro D, Furness RW (2002) Influences of food availability and predation on survival of kittiwakes. Ecology 83: 2516-2568

> Oro D, Cam E, Pradel R, Martínez-Abraín A (2004) Influence of food availability on demography and local population dynamics in a long-lived seabird. Proc Biol Sci 271: 387-396

Peron C, Authier M, Barbraud C, Delord K, Besson D, Weimerskirch $H$ (2010) Interdecadal changes in at sea distribution and abundance of subantarctic seabirds along a latitudinal gradient in the Southern Indian Ocean. Glob Change Biol 16:1895-1909

Phillips RA, Silk JRD, Croxall JP, Afanasyev V, Briggs DR (2004) Accuracy of geolocation estimates for flying seabirds. Mar Ecol Prog Ser 266:265-272

Pinaud D, Weimerskirch H (2005) Scale-dependent habitat use in a long-ranging central place predator. J Anim Ecol 74:852-853

Ramos R, Granadeiro JP, Nevoux M, Mougin JL, Dias MP, Catry P (2012) Combined spatio-temporal impacts of climate and longline fisheries on the survival of transequatorial marine migrant. PLoS ONE 7:e40822

> Ratikainen II, Gill JA, Gunnarson TG, Sutherland WJ, Kokko H (2008) When density dependence is not instantaneous: theoretical developments and management implications. Ecol Lett 11:184-198

Reiertsen TK, Erikstad KE, Barrett RT, Sandvik H, Yoccoz NG (2012) Climate fluctuations and differential survival of bridled and non-bridled common guillemots Uria aalge. Ecosphere 3:art52, doi:10.1890/ES12-00031R

Runge MC, Marra PP (2005) Modeling seasonal interactions in the population dynamics of migratory birds. In: Greenberg R, Marra PP (eds) Birds of two worlds: the ecology and evolution of migration. The John Hopkins University Press, Baltimore, MD, p 275-389

Sandvik H, Erikstad KE, Barrett RT, Yoccoz NG (2005) The effect of climate on adult survival in five species of North Atlantic seabirds. J Anim Ecol 74:817-831

Schaub M, Jakober H, Stauber W (2011) Demographic response to environmental variation in breeding stopover and non-breeding areas in a migratory passerine. Oecologia 167:445-459

> Seavy NE, Humple DL, Cormier RL, Gardali T (2012) Establishing the breeding provenance of a temperate-wintering North American passerine, the golden-crowned sparrow, using light-level geolocation. PLoS ONE 7: e34886

Skalski JR, Hoffmann A, Smith SG (1993) Testing the significance of individual- and cohort-level covariates in animal survival studies. In: Lebreton JD, North PM (eds) Marked individuals in the study of bird population. Birkhäuser Verlag, Basel, p 9-28

Skern-Mauritzen M, Johannesen E, Bjørge A, Øien N (2011) Baleen whale distributions and prey associations in the Barents Sea. Mar Ecol Prog Ser 426:289-301

> Smith PA, Gaston AJ (2012) Environmental variation and the demography and diet of thick-billed murres. Mar Ecol Prog Ser 454:237-249

Smith TM, Reynolds RW, Peterson TC, Lawrimore J (2008) Improvements to NOAA's historical merged land-ocean 
surface temperature analysis (1880-2006). J Clim 21: 2283-2296

Stearns SC (1992) The evolution of life histories. Oxford University Press, New York, NY

Steinacher M, Joos F, Froelicher TL, Plattner G, Doney SC (2009) Imminent ocean acidification in the Arctic projected with the NCAR global coupled carbon cycle-climate model. Biogeosciences 6:515-533

Stige LJ, Lajus DL, Chan KS, Dalpadado P, Basedow SL, Berchenko I, Stenseth NC (2009) Climatic forcing of plankton dynamics is stronger during low densities of planktivorous fish. Limnol Oceanogr 54:1025-1036

Stige LC, Ottersen G, Dalpadado P, Chan KS and others (2010) Direct and indirect climate forcing in a multispecies marine system. Proc Biol Sci 277:3411-3420

Ushakov NG, Ozhigin VK (1987) Formation of capelin year class abundance and features of their juvenile

Editorial responsibility: Rory Wilson,

Swansea, UK distribution affected by oceanological conditions. In: Loeng $\mathrm{H}$ (ed) The effect of oceanological conditions on the distribution and dynamics of commercial fish populations in the Barents Sea. Rep 3rd Soviet Norwegian Symposium 26-28 May 1986. PINRO, Murmansk, p 159-167

Wanless S, Frederiksen M, Daunt F, Scott BE, Harris MP (2007) Black-legged kittiwakes as indicators of environmental change in the North Sea: evidence from longterm studies. Prog Oceanogr 72:30-38

Welcker J, Moe B, Bech C, Fyhn M, Schultner J, Speakman JR, Gabrielsen GW (2010) Evidence for an energetic ceiling in free-ranging kittiwakes Rissa tridactyla. J Anim Ecol 79:205-213

Ylönen H, Sinervo B, Smith H (1998) Costs of reproduction. Proceedings of an Oikos seminar held at Jyvaskyla, Finland 7-12 January 1997 - Preface. Oikos 83:417-584

Submitted: April 18, 2013; Accepted: April 11, 2014

Proofs received from author(s): August 13, 2014 